Mr. T. J. Headlee: No. We tried it last year with apples.

Professor George A. Dean: The next paper is by P. J. Parrott.

\title{
CONTROL OF SUCKING INSECTS BY DUSTING
}

\author{
By P. J. Parrott, Geneva, N. $Y$.
}

Among the problems of pest control that confront the orchardist and general farmer, those bearing on dusting continue to attract attention. In a previous report the writer presented an outline of the scope and nature of his activities with respect to dusting, and announced some preliminary results relative to the effectiveness of materials in powdered form in controlling certain injurious insects. The present paper summarizes the results of experiments in continuation of previous work, considering especially the susceptibility of apple red bugs and various species of aphids.

\section{The Apple Red Bugs}

In the experiments with the bright red bug (Lygidea mendax Reuter) and the dark red bug (Heterocordylus malinus Reuter), dusting mixtures containing $0.25,0.50,1.0$, and 2.0 per cent nicotine, respectively, were toxic to the insects. The preparations with the highest amounts of nicotine gave, on an average, more uniform results and displayed higher killing power than those containing the smaller ratios. Mixtures with 0.25 per cent nicotine are probably too weak to obtain satisfactory control. Dusts containing 0.5 or more per cent nicotine should be used in rather liberal amounts and applied with care to destroy the majority of the insects and to avoid high dosage cost. Prevailing conceptions of dosage requirements for typical bearing orchards tend to underestimate the quantity of material necessary to accomplish effective results.

Efficient dusting mixtures against red bugs require a larger nicotine content than spraying mixtures, which makes the dosage cost for dusting higher than that for spraying. Dusting requires less time than spraying, resulting in appreciable economies in time and labor. At prevailing prices for materials dusting is more expensive than spraying. Considering the needs of average growers and cost of labor and materials, the apple red bugs can be more effectually and economically controlled by spraying than by dusting. In large commercial orchards dusting could doubtless be used to great advantage in a supplementary capacity to the usual spraying operations. 
Dusting and spraying experiments with the currant aphis (Myzus ribis Linnaeus) were conducted in a planting of 500 currant bushes, which provided for 100 plats of 5 plants each, thus permitting frequent tests of the different materials. The spraying mixture was composed of 1 pint of nicotine sulfate to 100 gallons of water to which were added 6 pounds of soap. The dusting preparations contained $0.50,1.00$, and 2.0 per cent nicotine, respectively, sulfur-lead arsenate (90-10) being used as the carrier of the nicotine. Each plat received three treatments, dusting material being applied at the rate of 1 pound per bush, and the spraying mixture at the rate of 2 gallons per bush.

Both dusting and spraying mixtures afforded efficient protection. All the treated plants contrasted strongly with the untreated plants, which displayed numerous discolored and distorted leaves that began to drop during midsummer. The foliage of the treated plants was more abundant and adhered to the plants long after the checks had been completely defoliated.

The dusting preparations showed a high rate of toxicity to the currant aphids. The condition of the foliage containing 0.5 per cent nicotine was not quite as satisfactory as that of the vines dusted with preparations containing 1 and 2 per cent nicotine, respectively. A small percentage of the leaves showed injury, but the curling was not of the severe type exhibited by the checks, and there was little, if any, premature defoliation.

\section{The Cabbage Aphis}

The experiments with the cabbage aphis (Aphis brassicae Linnaeus) provided for tests with dusting and spraying mixtures with different ratios of nicotine, in which all available types of machines for applying liquid and powdered insecticides were used. Soap and nicotine at standard strength, sulfur-lead arsenate (90-10) and lime dusts, containing $0.5,1.0$, and 2.0 per cent nicotine respectively, were toxic to the cabbage aphis. Two applications gave excellent control, resulting in yields of cabbage which were from 4 to 6 tons per acre according to the kind of treatment in excess of those of the check plats.

From the standpoint of economy and effectiveness, the most satisfactory treatment was a lime preparation (calcium hydrate) containing 2.00 per cent nicotine, applications being made at the rate of 20 pounds per acre with a "hand bellows duster." With power dusting machinery, from 35 to 40 pounds of material were required to secure effective control. Considering the results as a whole, dusting appears to be a very promising system of treatment for controlling the cabbage 
aphis. It has made a strong appeal to leading cabbage growers in this area who heretofore have been very lukewarm towards spraying as a method of combating the aphis. In the immediate vicinity of the experiments it has been estimated that dusting materials to the value of approximately $\$ 8,000.00$ were applied to cabbages.

For the control of cabbage aphis and cabbage worms we prefer, for the present, the formula which provides for 5 pounds nicotine sulfate, 15 pounds of powdered lead arsenate or calcium arsenate, and 80 pounds of hydrated lime. If the caterpillars are not very numerous, it is believed that the arsenical may safely be reduced to 10 pounds.

\section{The Potato Aphis}

Of the various insects considered in our experiments, the potato aphis (Macrosiphum solanifolii Ashmead) was the most difficult species to combat satisfactorily. It is apparently not as susceptible as the foregoing forms to common insecticides, and the dense foliage and matting of the vines constitute formidable obstacles to effective treatment which can only be overcome by painstaking work.

On the basis of the insects infesting the tips of the growing shoots, dehydrated copper-lead arsenate, containing 2 per cent nicotine, killed 52.3 per cent of the aphids at a dosage of 50 pounds per acre, and 83.2 per cent at a dosage of 90 pounds per acre. Nicotine and soap, using 100 gallons per acre destroyed 85.5 per cent of the aphids.

Notwithstanding the fact that many insects in some of the plats escaped, it should be noted that all the applications checked appreciably the rapid development of the aphids on the growing tips of the vines, which seemed to afford noticeable protection to the leaves. The plats that were left untreated displayed much discolored, withered foliage as the result of the uninterrupted feeding and breeding of the aphids. And one unacquainted with the plans of the tests had little difficulty in distinguishing the untreated plats from the treated plats.

\section{Conclusions}

In view of the data obtained from the foregoing experiments it is concluded that apple red bugs and certain aphids may be effectively controlled by thoro dusting with sulfur-lead arsenate or calcium hydrate containing nicotine sulfate. The outstanding advantage of dusting is speed of operation which effects noticeable economies in time and labor. A serious drawback is the high cost of the preparations, due chiefly to the large amount of nicotine required to make effective mixtures. Notwithstanding the economy in time and labor, dusting on the basis of existing prices for materials and labor has generally been more expensive than spraying, except possibly in the treatment of cabbages. 
One means of effective economy is to employ mixtures with the minimum amount of nicotine necessary to secure satisfactory control. The experiments as outlined indicate that for certain species of insects lower ratios of nicotine may be used than now generally prevail. Of vital importance in furthering an extensive employment of dusting for the control of sucking insects is the need of less expensive materials which function effectively as contact insecticides.

Mr. GlenN W. Herrick. These experiments are interesting to me as they point out clearly that in nearly any spraying operation, a certain number of the insects escape, no matter how thoroughly you may carry on the work. The efficiency of almost any insecticide in the field seems to depend in the final analysis on the effectiveness with which it is applied

President George A. Dean. The next paper on the program is by J. S. Houser and C. R. Neillie,

\section{AN ACCOUNT OF THE SUCCESSFUL USE OF THE AEROPLANE IN DUSTING TALL TREES INFESTED WITH LEAF EATING CATERPILLARS.}

By J. S. Houser and C. R. Neillie

(Withdrawn for publication in National Geographic Magazine, March, 1922.)

Mr. E. G. Kelly. What is the expense of this machine?

Mr. J. S. Houser. The greatest item of expense lies in the original cost of the plane, but when you consider that a Curtis plane can in these times be procured for fifteen thousand dollars, and that some of the liquid spraying machines used in New England cost five thousand dollars and over, the comparison is not so much out of the way, after all. The work that one can do in a day's time with an aeroplane equipped as was ours, or equipped as a real machine for the work should be equipped, will greatly exceed that of a liquid sprayer. Thus the saving in time and labor would more than offset the original excessive cost of the machine.

Mr. F. C. Craighead. What is your idea of the best wind conditions for application?

Mr. J. S. Houser. We used a crossing wind. Under other conditions you might want to fly directly into the wind. We found in our trial flights at $\mathrm{McCook}$ field that we could get an excellent spread of the poison by flying into the wind, and that would allow one to fly higher than otherwise.

Mr. F. C. Craighead. How far to the side did you fly? 